\title{
Anesthetic management of a dog with severe subaortic stenosis and mitral valve disease complicated with atrial fibrillation undergoing ovariohysterectomy
}

\author{
Mario Arenillas*, Alicia Caro-Vadillo and Ignacio A. Gómez de Segura \\ Department of Animal Medicine and Surgery, Facultad de Veterinaria, Hospital Clínico Veterinario, Universidad \\ Complutense de Madrid, Madrid, Spain
}

\begin{abstract}
The anesthetic management in patients with subaortic stenosis and mitral valve disease should involve intensive monitoring and the anesthesiologist's main concern is to ensure oxygen delivery and tissue perfusion. Since anesthetic procedures in such patients are rare, there is no previous report about the anesthetic management. A 5.5-year old, 32-kg Boxer, suffering a severe heart disease due to a final stage subaortic stenosis and mitral insufficiency, was anesthetized for an ovariohysterectomy to remove an ovarian tumor that was producing high-volume ascites. Methadone $(0.3 \mathrm{mg}$ $\left.\mathrm{kg}^{-1}\right)$ was administered intramuscularly (IM) for pre-anesthetic medication, etomidate $\left(1.3 \mathrm{mg} \mathrm{kg}^{-1}\right)$ and midazolam $(0.2$ $\mathrm{mg} \mathrm{kg}{ }^{-1}$ ) were used for the induction of anesthesia and after endotracheal intubation, anesthesia was maintained with sevoflurane vaporized in oxygen and air. Fentanyl $\left(5-10 \mu \mathrm{g} \mathrm{kg}^{-1} \mathrm{~h}^{-1}\right)$ and paracetamol $\left(15 \mathrm{mg} \mathrm{kg}^{-1}\right)$ were administered to improve analgesia. Previous persistent atrial fibrillation was refractory to medication (digoxin, diltiazem, and pimobendan) and continued during the anesthetic procedure. Dobutamine $\left(1.5-5 \mu \mathrm{g} \mathrm{kg}^{-1}\right.$ minute $\left.{ }^{-1}\right)$ helped to maintain mean arterial blood pressure above $60 \mathrm{mmHg}$. Epidural morphine $\left(0.1 \mathrm{mg} \mathrm{kg}^{-1}\right)$ and incisional bupivacaine $\left(2 \mathrm{mg} \mathrm{kg}^{-1}\right)$ were administered at the end of surgery to provide postoperative analgesia. Anesthesia was otherwise uneventful, and recovery was considered excellent.
\end{abstract}

Keywords: Anesthesia, Atrial fibrillation, Dog, Mitral, Subaortic stenosis.

\section{Introduction}

Anesthesia in severe cardiac patients is challenging and has special considerations due to their inability to ensure an adequate cardiac output (CO) despite physiological compensatory mechanisms. In addition to physical examination and a complete blood work, including blood count, chemistry panel, and electrolytes, the assessment of the electrocardiogram, blood pressure, thoracic radiographs, and echocardiogram should be accomplished to the patients suffering from heart disease (Congdon, 2014; Robinson and Borgeat, 2016). Heart diseases affect in a variety of ways, the cardiovascular function and anesthetic drugs should be considered based on the cardiovascular-sparing effects. Although there are some general principles applicable to patients with cardiovascular disease, some considerations should be taken to adapt the anesthetic plan depending on the patient's cardiovascular status. Anesthetic management in the patients with subaortic stenosis (SAS) and mitral valve disease (MVD) should involve intensive monitoring while avoiding significant change in heart rate (HR), sinus rhythm, blood pressure, and intravascular volume. Thus, the anesthesiologist's main concern is to prevent the increase in myocardial oxygen demand and decreased tissue perfusion (Robinson and Borgeat, 2016).
There are no reported cases of anesthesia in a dog presenting the aforementioned heart diseases, thus this case report describes the anesthetic management of a dog with severe chronic and degenerative heart disease undergoing an ovariohysterectomy.

\section{Case Details}

A 5.5-year-old Boxer bitch weighing $32 \mathrm{~kg}$ was referred to the Veterinary Teaching Hospital with lethargy, anorexia, and abdominal distension. Two weeks before, the dog had been presented to the referring veterinarian with a suppurative mass over the stifle and abdominal distension. Prior to the surgical removal of the mass (diagnosed as a mastocytoma) and due to the previous history of heart disease, a thorough examination of the heart condition was suggested. The echocardiography showed a severe SAS with a pressure gradient of 108 $\mathrm{mmHg}$ and mitral insufficiency associated to thickening of the valve with severe dilation of the left chambers of the heart. Ejection fraction, Simpson Method, and fractional shortening, Teizchold Method, were decreased ( $40.1 \%$ and $19.6 \%$, respectively). Systolic function was reduced, and pulmonary hypertension was not observed. Thereafter, the referring veterinarian prescribed ciprofloxacin [250 mg twice a day (BID)], prednisone [10 mg once a day ( QD)], benazepril (10 mg BID), and 
furosemide (40 mg BID) orally, and referred the patient to the Teaching Hospital.

On presentation at the Hospital, the dog was depressed, had weak peripheral pulse and positive jugular pulse. Auscultation revealed a heart murmur (III/VI) and the electrocardiography showed atrial fibrillation (AF) and left bundle branch block, usually associated with left cardiac chambers enlargement. HR was 250 beats per minute (bpm). Among other age-related findings (and not associated to the current complain), the chest radiographs showed cardiomegaly with a vertebral heart score of 13, dorsal displacement of the trachea, and the presence of interstitial-alveolar pattern in the proximal third of the seventh intercostal space in the lateral projection, and at the right medium and caudal lobes in the ventrodorsal projection, most likely to be cardiogenic pulmonary edema. Other findings were costochondral calcifications, deforming spondylosis, and bony bridges among sternebrae. Additionally, on abdominal radiographs, there was loss of peritoneal detail, most likely representing peritoneal effusion. Hence, abdominocentesis was performed and six liters of modified transudate were obtained. Afterward, ultrasound of the abdomen revealed the presence of a mass close to the right kidney suggestive of ovarian tumor. No other findings were remarkable, with the exception of iliac lymphadenopathies. Evaluation of the ovarian mass with cytology of a fine needle aspirate obtained from the ovarian revealed an adenocarcinoma. The presence of abdominal effusion is a common clinical sign with this type of tumor in the bitch (Bertazzolo et al., 2012). Based on the clinical findings, ovariohysterectomy was proposed, as an alternative to humane euthanasia, and eventually the owners gave their informed consent for the surgical procedure.

Initially, digoxin $(0.125 \mathrm{mg}$ BID; Digoxina $0.25 \mathrm{mg}$, Kern Pharma), diltiazem (15 mg BID; Diltiazem Sandoz $60 \mathrm{mg}$, Sandoz Farmaceutica), and pimobendan (6.125 mg BID; Vetmedin $5 \mathrm{mg}$, Boehringer Ingelheim) were added to the previous oral treatment. A stage $D$ of valvular disease was considered as there were signs of heart failure refractory to the therapy (Atkins et al., 2009). Surgery was scheduled for 2 weeks later. In between, digoxin check-up showed normal values $\left(1.8 \mathrm{ng} \mathrm{ml}^{-1}\right)$.

The dog was fasted the night before the surgery although ad libitum water was available. Two hours before surgery, all the prescribed medications were given orally with the exception of furosemide (Seguril $20 \mathrm{mg}$ $2 \mathrm{ml}^{-1}$, Aventis; $1 \mathrm{mg} \mathrm{kg}^{-1}$ ) given intravenously (IV). On preoperative physical examination, the patient was on a poor body condition, presented a cardiac murmur (III/ $\mathrm{VI}), \mathrm{AF}$, and bundle branch block with tachycardia (170$200 \mathrm{bpm}$ ), a considerable abdominal distension with positive ascitic wave and positive jugular pulse. Most remarkable findings in blood work were an increase of uremia $\left(125 \mathrm{mg} \mathrm{dl}^{-1}\right)$, hypoproteinemia $\left(4.1 \mathrm{~g} \mathrm{dl}^{-1}\right)$, hypoalbuminemia $\left(2.2 \mathrm{~g} \mathrm{dl}^{-1}\right)$, and hypocalcemia ( 8.8 $\left.\mathrm{mg} \mathrm{dl}{ }^{-1}\right)$; the remaining parameters were within the normal range for the species. It was classified as an American Society of Anesthetists physical scale of IV. Methadone (Semfortan $10 \mathrm{mg} \mathrm{ml}{ }^{-1}$, Dechra; 0.3 $\mathrm{mg} \mathrm{kg}^{-1}$ ) was administered IM for pre-anesthetic medication. After 20 minutes, mild sedation was achieved and $500 \mathrm{ml}$ of transudate were obtained via abdominal drainage. Both an $18 \mathrm{G}$ and a $22 \mathrm{G}$ catheter were placed in the cephalic vein and the dorsopedal artery, respectively. After 5-minute preoxygenation (5 1 minute $^{-1}$ ) by mask, anesthesia was induced with etomidate (Etomidato-Lipuro $2 \mathrm{mg} \mathrm{ml}^{-1}$, B.Braun; 1.3

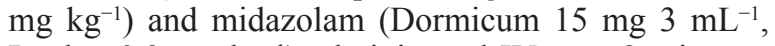
Roche; $0.2 \mathrm{mg} \mathrm{kg}^{-1}$ ) administered IV over 2 minutes, and the trachea was intubated with a $10-\mathrm{mm}$ internal diameter cuffed endotracheal tube and connected to a rebreathing circuit. An intravenous dobutamine

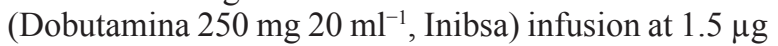
$\mathrm{kg}^{-1}$ minute ${ }^{-1}$ was started immediately after anesthetic induction. Anesthesia was initially maintained with $2 \%$ sevoflurane (SevoFlo, Abbott) vaporized in 100\% inspired oxygen. Once transferred to the theatre, the patient was connected to an anesthesia workstation (Julian, Dräger) and anesthesia was maintained with end tidal concentrations of sevoflurane $\left(\mathrm{Et}_{\mathrm{SEVO}}\right)$ between $1.3 \%$ and $1.7 \%$ vaporized in oxygen and air $(80 \%$ and $20 \%$, respectively).

Ranitidine (Zantac $10 \mathrm{mg} \mathrm{ml}^{-1}$, GlaxoSmithKline; $1 \mathrm{mg} \mathrm{kg}$ ) and diphenhydramine (Antihistamínico $25 \mathrm{mg} \mathrm{ml}^{-1}$, Syva; $1 \mathrm{mg} \mathrm{kg}^{-1}$ ) were administered subcutaneously after anesthetic induction to prevent the potential histaminergic effects of the mastocytoma (London and Seguin, 2003). In addition, cefazolin IV (Cefazolina $1 \mathrm{~g}$, Normon; $22 \mathrm{mg} \mathrm{kg}^{-1}$ ) was administered as a prophylactic antibiotic.

Persistent tachycardia (220-240 bpm) with AF and left bundle branch block were observed throughout the surgery. Mean arterial pressure remained steady $(70-80 \mathrm{mmHg})$ by adjusting the continuous rate infusion (CRI) of dobutamine $\left(1.5-5 \mu \mathrm{g} \mathrm{kg}^{-1}\right.$ minute $\left.^{-1}\right)$. Oxygen saturation of hemoglobin $(>95 \%)$ and body temperature $\left(37.5^{\circ} \mathrm{C}-38.5^{\circ} \mathrm{C}\right)$, were within physiologic ranges during the whole procedure. An air-warming blanket was used (Bair Hugger, 3M) during the surgery. Moderate hypercapnia $(46-62 \mathrm{mmHg}$ ) was allowed during spontaneous ventilation to avoid the potential negative effects of mechanical ventilation, such as the rise in intra-thoracic pressure, which may affect the right heart venous return, limiting the cardiac filling and therefore, decreasing CO (Dugdale, 2007).

An intravenous CRI of fentanyl (Fentadon 0.05 $\mathrm{mg} \mathrm{ml}{ }^{-1}$, Dechra; 5-10 $\mu \mathrm{g} \mathrm{kg}^{-1} \mathrm{~h}^{-1}$ ) was deemed to improve intraoperative analgesia and reduce inhalatory anesthetic requirements. Fluid therapy with Lactated Ringer's solution (Lactato-RingerVet $500 \mathrm{~mL}$, B.Braun) was adjusted to $1-2 \mathrm{ml} \mathrm{kg}^{-1} \mathrm{~h}^{-1}$ depending on fentanyl infusion to avoid fluid overload. In addition, $15 \mathrm{mg} \mathrm{kg}^{-1}$ of paracetamol (Paracetamol Kabi $10 \mathrm{mg} \mathrm{ml}^{-1}$, Fresenius Kabi) were administered 
over 20 minutes IV as a part of a multimodal analgesic approach.

Once the surgery finished, a subcutaneous injection of bupivacaine (2 $\mathrm{mg} \mathrm{kg}^{-1}$; Bupivacaina $0.5 \%$, B.Braun) was used in the surgical wound and an epidural administration of morphine (Cloruro Mórfico 1\%, B.Braun; $0.1 \mathrm{mg} \mathrm{kg}^{-1}$ ) diluted with saline (Fisiovet 100 $\mathrm{ml}$, B.Braun; total epidural volume $0.2 \mathrm{ml} \mathrm{kg}^{-1}$ ) were performed to provide postoperative analgesia. Total general anesthesia and surgery times were 73 and 56 minutes, respectively.

Arterial blood gases at the end of surgery revealed acidemia $(\mathrm{pH}=7.19)$ due to an expected respiratory acidosis $\left(\mathrm{PaCO}_{2}=60.4 \mathrm{mmHg}\right)$. No other findings were relevant, thus no further actions were considered.

The dog was uneventfully recovered from anesthesia and was transferred to the intensive care unit (ICU). There, enoxaparin (Clexane $60 \mathrm{mg} 0.6 \mathrm{ml}^{-1}$, Aventis; $0.8 \mathrm{mg} \mathrm{kg}^{-1}$ ) was administered every eight hours as well as all the aforementioned cardiac medication. The dobutamine infusion was gradually reduced until finally discontinued 35 hours after anesthesia's end. Non-invasive mean arterial pressure remained above $60 \mathrm{mmHg}$ at all the times. Analgesia was assessed every hour with the Short Form of the Glasgow Composite Measure Pain Scale, and buprenorphine (Buprecare $0.3 \mathrm{mg} \mathrm{mL}$, Divasa-Farmavic; $15 \mu \mathrm{g} \mathrm{kg}^{-1} \mathrm{SC}$ ) was administered every 8 hours. Although depressed mood, stance in the ICU was otherwise uneventful and the patient was discharged 2 days after the surgery.

\section{Discussion}

An anesthetic management using sedative and anesthetic drugs with cardiovascular-sparing effects, associated with a multimodal analgesic approach and cardiovascular support, allowed adequate cardiovascular stability in this case. The main complications observed were a moderate hypercapnia and cardiac arrhythmias associated with the cardiac condition. Eventually, the overall outcome of the patient was satisfactory.

SAS is the most common form of aortic stenosis in the dog and Boxer is one of the breeds predominantly affected (O'Grady et al., 1989; Kienle et al., 1994; Hollmer et al., 2008). In this case, the CO is highly dependent on HR because the outflow obstruction in the aorta impedes stroke volume (SV) to increase (Scarabelli and Bradbrook, 2016). The prognosis is based on the pressure gradient along the valve and common drugs used to treat the clinical signs are betaadrenergic receptor blockers. Dogs with SAS and mild pressure gradients (16-35 $\mathrm{mmHg}$ ) commonly may experience no morbidity but SAS with moderate $(36-80 \mathrm{mmHg})$ to severe $(>80 \mathrm{mmHg})$ gradients lead to left ventricle (LV) failure, pulmonary edema and high risk of sudden death (O'Grady et al., 1989; Kienle et al., 1994; Reilly et al., 2013). In the current case, the pressure gradient was $108 \mathrm{mmHg}$ and the SV was reduced leading to an overall reduction in $\mathrm{CO}$. In addition, a cardiac defect such as the MVD which is usually found with SAS (Kienle et al., 1994) was also present. The MVD produces insufficiency, reduced CO, and maladaptive compensatory mechanisms. Therefore, methadone was chosen for pre-anesthetic medication as opioids have limited cardiovascular effects, but they also have inhalant anesthetic's minimum alveolar concentration sparing effects in dogs (Credie et al., 2010; Williamson et al., 2017).

Methadone was expected to provide adequate perioperative sedation and analgesia (Hunt et al., 2013). Moreover, it may decrease the $\mathrm{HR}$, but maintaining CO, and increasing $\mathrm{SV}$, which reduces oxygen myocardial consumption (Perkowski and Oyama, 2015). Therefore, methadone may be desirable as tachycardia and AF increase myocardial oxygen demand and reduce $\mathrm{CO}$.

Etomidate was used for anesthetic induction as it produces minimal cardiovascular depression, i.e., HR, blood pressure, left ventricular pressures, contractility, and myocardial oxygen remains unchanged after its administration (Nagel et al., 1979; Carter et al., 2017). Anesthetic induction with etomidate may produce some adverse effects like excitement, myoclonus or vomiting (Muir and Mason, 1989), thus midazolam was combined to counteract these effects. Most likely, midazolam may reduce the dose of etomidate as when it is combined with other common induction agents such as propofol or alfaxalone (Liao et al., 2017). Although midazolam may reduce systolic blood pressure during co-induction with propofol in healthy dogs, values remained within an acceptable range (Hopkins et al., 2014). Additionally, propofol or alfaxalone could have been chosen to induce anesthesia but they might affect negatively systemic vascular resistance (SVR) (Scarabelli and Bradbrook, 2016), while etomidate has a better cardiovascular profile (Sams et al., 2008; Rodriguez et al., 2012).

Isoflurane and sevoflurane are suitable volatile agents for maintenance of anesthesia as both provide similar clinical effects (Bennett et al., 2008). Sevoflurane produces a more rapid anesthetic induction (Johnson et al., 1998; Cantalapiedra et al., 2000) and faster recovery from anesthesia (Eger, 1994). Some studies have suggested that both isoflurane and sevoflurane produce similar cardiovascular depression, but the latter producing a lesser respiratory depression (Galloway et al., 2004). However, evidence of clinically relevant differences between quality and speed of recovery between isoflurane and sevoflurane anesthesia in dogs remains controversial; some studies showed a faster recovery using sevoflurane (Lopez et al., 2009) while others found no differences in recovery times (Johnson et al., 1998; Cantalapiedra et al., 2000; Love et al., 2007).

Sevoflurane causes dose-dependent hypotensive effects associated with vasodilation, decreases in myocardial contractility and left ventricular afterload (Eger, 1994; Hettrick et al., 1996). Considering the diagnosed 
reduction in myocardial contractility with severe ventricular dysfunction, together with the likely further reduction produced by sevoflurane in the present case, the administration of dobutamine was considered from the beginning of the anesthesia. Dobutamine has dose-dependent positive inotropic effects and may increase blood pressure without affecting left atrial pressure or afterload (Goya et al., 2018). This drug increases arterial pressure and enhances myocardial contractility in isoflurane-anesthetized dogs with surgically induced mitral insufficiency (Goya et al., 2018). Thus, the inotropic effect counteracted the cardiovascular effect without increasing afterload. The use of vasoconstrictors (e.g., phenylephrine and norepinephrine) increases SVR, which therefore would increase left atrial pressure (Scarabelli and Bradbrook, 2016) and, for that reason they were not considered in this case. Intravenous infusion of fentanyl was not only administered to enhance intraoperative analgesia but also further reduce $\mathrm{Et}_{\mathrm{SEVO}}$ (Reilly et al., 2013; Suarez et al., 2017). In the present case, $\mathrm{Et}_{\mathrm{SEVO}}$ was maintained between $1.3 \%$ and $1.7 \%$ to reach an acceptable depth of anesthesia which means a reduction of $20 \%-40 \%$ of the MAC of sevoflurane required to prevent purposeful movements in dogs (Yamashita et al., 2012).

Recommendations on the administration of antihistaminergic drugs to avoid cardiorespiratory effects of histamine through actions on $\mathrm{H} 1$ and $\mathrm{H} 2$ receptors in patients with mastocytoma is still controversial. Preventive treatment has been recommended (London and Seguin, 2003) but more recently, its true efficacy has been questioned in anesthetized dogs undergoing excision of mast cell tumors (Sanchez et al., 2017). Both diphenhydramine and ranitidine were given following the former recommendations while no adverse effects were expected after their administration.

Moreover, $\mathrm{AF}$ is a common arrhythmia associated with severe atrial enlargement and severe mitral regurgitation in dogs. The characteristic uncoordinated atrial activity impedes atrial contraction leading to reduced $\mathrm{CO}$ further aggravated in the presence of tachycardia. Usual treatments include digoxin, beta-blockers, and calcium channel blockers to slow AV conduction (Miyamoto et al., 2001; Congdon, 2014). Lidocaine has been used to treat satisfactorily vagally associated AF (Moise et al., 2005; Pariaut et al., 2008) and reduces the sevoflurane MAC in dogs (Wilson et al., 2008). However, lidocaine may cause cardiovascular depression in dogs (Robinson and Borgeat, 2016) and increases in HR, pulmonary arterial pressure, and stroke index (Nunes de Moraes et al., 1998). Conversion to sinus rhythm with lidocaine in patients suffering an underlying severe cardiac disease is not always possible (Congdon, 2014). In addition, AF was already refractory to medical therapy in the current case, thus lidocaine and any further cardiovascular depression associated to it was avoided. Amiodarone is a class III antiarrhythmic used to treat $\mathrm{AF}$ but has been related to adverse effects such as increased blood histamine concentrations producing skin reactions, tachycardia, hypotension, and bronchospasm (Cober et al., 2009); therefore, it was considered inappropriate in the present case.

Paracetamol is a centrally acting analgesic with weak anti-inflammatory properties but less gastrointestinal and cardiovascular side effects compared with nonsteroidal anti-inflammatory drugs (NSAIDs) (Jahr and Lee, 2010). It is not as widely used in veterinary patients as in human medicine, probably because of its toxic effects in cats and scarce reports of its use in dogs. However, paracetamol might be useful in a multimodal analgesic approach (Mburu et al., 1998; White et al., 2017). Although other NSAIDs commonly used in dogs such as meloxicam or carprofen could have been used in the present case, the side effects of these drugs, such as the gastrointestinal, renal, or increase in bleeding, were considered (Luna et al., 2007). Furthermore, common situations associated with anesthesia, such as hypotension or hypovolemia, can enhance the NSAIDs' adverse effects on renal function (Lomas and Grauer, 2015).

Bupivacaine is a potent amide type local anesthetic with a long duration of action widely used in veterinary medicine (Webb and Pablo, 2009). It was administered incisional in this patient to improve postoperative analgesia. Although intra-peritoneal administration of bupivacaine could have enhanced the analgesic effect (Carpenter et al., 2004; Campagnol et al., 2012), the presence of ascites discouraged it.

Finally, the epidural administration of morphine was considered to complete the multimodal analgesic approach as it provides postoperative analgesia without causing further hemodynamic depression in the dogs (Naganobu et al., 2004; Kona-Boun et al., 2006; Perez et al., 2013). The more hydrophilic nature of morphine provides a longer duration of the analgesic effect when given epidurally compared to other opioids with higher lipophilicity (e.g., fentanyl), thus with a faster systemic absorption (Valverde et al., 1992). Combination of morphine with local anesthetics by the epidural route prolongs analgesic effects but may produce some cardiorespiratory depression considered acceptable for healthy patients (Kona-Boun et al., 2006) but potentially harmful for an hemodynamic unstable patient such as the one in this case.

In conclusion, a multimodal analgesic approach, a reduced concentration of sevoflurane for anesthetic maintenance and cardiovascular support under spontaneous ventilation, together with intensive monitoring, were able to maintain an adequate anesthesia in a severe cardiac patient undergoing ovariohysterectomy.

\section{Conflict of interest}

The authors declare that there is no conflict of interest.

\section{References}

Atkins, C., Bonagura, J., Ettinger, S., Fox, P., Gordon, S., Haggstrom, J., Hamlin, R., Keene, B., Luis- 
Fuentes, V. and Stepien, R. 2009. Guidelines for the diagnosis and treatment of canine chronic valvular heart disease. J. Vet. Intern. Med. 23, 1142-1150.

Bennett, R.C., Fancy, S.P., Walsh, C.M., Brown, A.J. and Taylor, P.M. 2008. Comparison of sevoflurane and isoflurane in dogs anaesthetised for clinical surgical or diagnostic procedures. J. Small Anim. Pract. 49, 392-397.

Bertazzolo, W., Bonfanti, U., Mazzotti, S. and Gelain, M.E. 2012. Cytologic features and diagnostic accuracy of analysis of effusions for detection of ovarian carcinoma in dogs. Vet. Clin. Pathol. 41, 127-132.

Campagnol, D., Teixeira-Neto, F.J., Monteiro, E.R., Restitutti, F. and Minto, B.W. 2012. Effect of intraperitoneal or incisional bupivacaine on pain and the analgesic requirement after ovariohysterectomy in dogs. Vet. Anaesth. Analg. 39, 426-430.

Cantalapiedra, A.G., Laredo, F., Villanueva, B. and Pereira, J.L. 2000. Comparison between isoflurane and sevoflurane anaesthesia in dogs. Vet. Anaesth. Analg. 27, 54.

Carpenter, R.E., Wilson, D.V. and Evans, A.T. 2004. Evaluation of intraperitoneal and incisional lidocaine or bupivacaine for analgesia following ovariohysterectomy in the dog. Vet. Anaesth. Analg. 31, 46-52.

Carter, J.E., Motsinger-Reif, A.A., Krug, W.V. and Keene, B.W. 2017. The effect of heart disease on anesthetic complications during routine dental procedures in dogs. J. Am. Anim. Hosp. Assoc. 53, 206-213.

Cober, R.E., Schober, K.E., Hildebrandt, N., Siroska, E. and Riesen S.C. 2009. Adverse effects of intravenous amiodarone in 5 dogs. J. Vet. Intern. Med. 23, 657-661.

Congdon, J.M. 2014. Cardiovascular disease. In Canine and feline anesthesia and co-existing disease. Eds., Snyder, L.B.C. and Johnson, R.A. Hoboken, NJ: John Wiley \& Sons, Inc., pp: 1-54.

Credie, R.G., Teixeira Neto, F.J., Ferreira, T.H., Aguiar, A.J., Restitutti, F.C. and Corrente, J.E. 2010. Effects of methadone on the minimum alveolar concentration of isoflurane in dogs. Vet. Anaesth. Analg. 37, 240-249.

Dugdale, A. 2007. The ins and outs of ventilation-1. Basic principles. In Pract. 29, 186-193.

Eger, E.I. 1994. New Inhaled Anesthetics. Anesthesiology 80, 906-922.

Galloway, D.S., Ko, J.C., Reaugh, H.F., Mandsager, R.E., Payton, M.E., Inoue, T. and Portillo, E. 2004. Anesthetic indices of sevoflurane and isoflurane in unpremedicated dogs. J. Am. Vet. Med. Assoc. 225, 700-704.

Goya, S., Wada, T., Shimada, K., Hirao, D. and Tanaka, R. 2018. Dose-dependent effects of isoflurane and dobutamine on cardiovascular function in dogs with experimental mitral regurgitation. Vet. Anaesth. Analg. 45, 432-442.

Hettrick, D.A., Pagel, P.S. and Warltier, D.C. 1996. Desflurane, sevoflurane, and isoflurane impair canine left ventricular-arterial coupling and mechanical efficiency. Anesthesiology 85, 403413.

Hollmer, M., Willesen, J.L., Jensen, A.T. and Koch, J. 2008. Aortic stenosis in the Dogue de Bordeaux. J. Small Anim. Pract. 49, 432-437.

Hopkins, A., Giuffrida, M. and Larenza, M.P. 2014. Midazolam, as a co-induction agent, has propofol sparing effects but also decreases systolic blood pressure in healthy dogs. Vet. Anaesth. Analg. 41, 64-72.

Hunt, J.R., Attenburrow, P.M., Slingsby, L.S. and Murrell, J.C. 2013. Comparison of premedication with buprenorphine or methadone with meloxicam for postoperative analgesia in dogs undergoing orthopaedic surgery. J. Small Anim. Pract. 54, 418424.

Jahr, J.S. and Lee, V.K. 2010. Intravenous acetaminophen. Anesthesiol. Clin. 28, 619-645.

Johnson, R.A., Striler, E., Sawyer, D.C. and Brunson, D.B. 1998. Comparison of isoflurane with sevoflurane for anesthesia induction and recovery in adult dogs. Am. J. Vet. Res. 59, 478-481.

Kienle, R.D., Thomas, W.P. and Pion, P.D. 1994. The natural clinical history of canine congenital subaortic stenosis. J. Vet. Intern. Med. 8, 423-431.

Kona-Boun, J.J., Cuvelliez, S. and Troncy, E. 2006. Evaluation of epidural administration of morphine or morphine and bupivacaine for postoperative analgesia after premedication with an opioid analgesic and orthopedic surgery in dogs. J. Am. Vet. Med. Assoc. 229, 1103-1112.

Liao, P., Sinclair, M., Valverde, A., Mosley, C., Chalmers, H., Mackenzie, S. and Hanna, B. 2017. Induction dose and recovery quality of propofol and alfaxalone with or without midazolam coinduction followed by total intravenous anesthesia in dogs. Vet. Anaesth. Analg. 44, 1016-1026.

Lomas, A.L. and Grauer, G.F. 2015. The renal effects of NSAIDs in dogs. J. Am. Anim. Hosp. Assoc. 51, 197-203.

London, C.A. and Seguin, B. 2003. Mast cell tumors in the dog. Vet. Clin. North Am. Small Anim. Pract. 33, 473-489.

Lopez, L.A., Hofmeister, E.H., Pavez, J.C. and Brainard, B.M. 2009. Comparison of recovery from anesthesia with isoflurane, sevoflurane, or desflurane in healthy dogs. Am. J. Vet. Res. 70, 1339-1344.

Love, E.J., Holt, P.E. and Murison, P.J. 2007. Recovery characteristics following maintenance of anaesthesia with sevoflurane or isoflurane in dogs 
premedicated with acepromazine. Vet. Rec. 161, 217-221.

Luna, S.P., Basilio, A.C., Steagall, P.V., Machado, L.P., Moutinho, F.Q., Takahira, R.K. and Brandão, C.V. 2007. Evaluation of adverse effects of long-term oral administration of carprofen, etodolac, flunixin meglumine, ketoprofen, and meloxicam in dogs. Am. J. Vet. Res. 68, 258-264.

Mburu, D.N., Mbugua, S.W., Skoglund, L.A. and Lokken, P. 1988. Effects of paracetamol and acetylsalicylic acid on the post-operative course after experimental orthopaedic surgery in dogs. J. Vet. Pharmacol. Ther. 11, 163-170.

Miyamoto, M., Nishijima, Y., Nakayama, T. and Hamlin, R.L. 2001. Acute cardiovascular effects of diltiazem in anesthetized dogs with induced atrial fibrillation. J. Vet. Intern. Med. 15, 559-563.

Moise, N.S., Pariaut, R., Gelzer, A.R., Kraus, M.S. and Jung, S.W. 2005 Cardioversion with lidocaine of vagally associated atrial fibrillation in two dogs. J. Vet. Cardiol. 7, 143-148.

Muir, W.W. 3rd and Mason, D.E. 1989. Side effects of etomidate in dogs. J. Am. Vet. Med. Assoc. 194, 1430-1434.

Naganobu, K., Maeda, N., Miyamoto, T., Hagio, M., Nakamura, T. and Takasaki, M. 2004. Cardiorespiratory effects of epidural administration of morphine and fentanyl in dogs anesthetized with sevoflurane. J. Am. Vet. Med. Assoc. 224, 67-70.

Nagel, M.L., Muir, W.W. and Nguyen, K. 1979. Comparison of the cardiopulmonary effects of etomidate and thiamylal in dogs. Am. J. Vet. Res. 40, 193-196.

Nunes de Moraes, A., Dyson, D.H., O'Grady, M.R., McDonell, W.N. and Holmberg, D.L. 1998. Plasma concentrations and cardiovascular influence of lidocaine infusions during isoflurane anesthesia in healthy dogs and dogs with subaortic stenosis. Vet. Surg. 27, 486-497.

O'Grady, M.R., Holmberg, D.L., Miller, C.W. and Cockshutt, J.R. 1989. Canine congenital aortic stenosis: a review of the literature and commentary. Can. Vet. J. 30, 811-815.

Pariaut, R., Moise, N.S., Koetje, B.D., Flanders, J.A., Hemsley, S.A., Farver, T.B., Gilmour, R.F. Jr, Gelzer, A.R., Kraus, M.S. and Otani, N.F. 2008. Lidocaine converts acute vagally associated atrial fibrillation to sinus rhythm in German Shepherd dogs with inherited arrhythmias. J. Vet. Intern. Med. 22, 1274-1282.

Perez, T.E., Grubb, T.L., Greene, S.A., Meyer, S., Valdez, N., Bingman, J. and Farnsworth, R. 2013. Effects of intratesticular injection of bupivacaine and epidural administration of morphine in dogs undergoing castration. J. Am. Vet. Med. Assoc. 242, 631-642.

Perkowski, S. and Oyama, M. 2015. Pathophysiology and anesthetic management of patients with cardiovascular disease. In Veterinary anesthesia and analgesia. Eds., Grimm, K., Lamont, L., Tranquilli, W., Greene, S. and Robertson, S. Oxford, UK: Wiley-Blackwell, pp: 496-510.

Reilly, S., Seddighi, R., Egger, C.M., Rohrbach, B.W., Doherty, T.J., Qu, W. and Johnson, J.R. 2013. The effect of fentanyl on the end-tidal sevoflurane concentration needed to prevent motor movement in dogs. Vet. Anaesth. Analg. 40, 290-296.

Robinson, R. and Borgeat, K. 2016. Cardiovascular disease. In BSAVA manual of canine and feline anaesthesia and analgesia, 3rd ed. Eds., DukeNovakovski, T., de Vries, M. and Seymour, C. Gloucester, UK: British Small Animal Veterinary Association, pp: 283-313.

Rodriguez, J.M., Munoz-Rascon, P., NavarreteCalvo, R., Gomez-Villamandos, R.J., Dominguez Perez, J.M., Fernandez Sarmiento, J.A., Quiros Carmona, S. and Granados Machuca, M.M. 2012. Comparison of the cardiopulmonary parameters after induction of anaesthesia with alphaxalone or etomidate in dogs. Vet. Anaesth. Analg. 39, 357-365.

Sams, L., Braun, C., Allman, D. and Hofmeister, E. 2008. A comparison of the effects of propofol and etomidate on the induction of anesthesia and on cardiopulmonary parameters in dogs. Vet. Anaesth. Analg. 35, 488-494.

Sanchez, A., Valverde, A., Sinclair, M., Mosley, C., Singh, A., Mutsaers, A.J., Hanna, B., Johnson, R., Gu, Y. and Beaudoin-Kimble, M. 2017. Antihistaminic and cardiorespiratory effects of diphenhydramine hydrochloride in anesthetized dogs undergoing excision of mast cell tumors. J. Am. Vet. Med. Assoc. 251, 804-813.

Scarabelli, S. and Bradbrook, C. 2016. Anaesthesia of the patient with cardiovascular disease part 2: anaesthesia for specific disorders. Companion Anim. 21, 337-344.

Suarez, M.A., Seddighi, R., Egger, C.M., Rohrbach, B.W., Cox, S.K., KuKanich, B.K. and Doherty, T.J. 2017. Effect of fentanyl and lidocaine on the endtidal sevoflurane concentration preventing motor movement in dogs. Am. J. Vet. Res. 78, 12-16.

Valverde, A., Conlon, P.D., Dyson, D.H. and Burger, J.P. 1992. Cisternal CSF and serum concentrations of morphine following epidural administration in the dog. J. Vet. Pharmacol. Ther. 15, 91-95.

Webb, A.I. and Pablo, L.S. 2009. Local anesthetics. In Veterinary pharmacology and therapeutics, 9th ed. Eds., Riviere, J.E. and Papich, M.G. Oxford, UK: Willey-Blackwell, pp: 381-399.

White, D.M., Mair, A.R. and Martinez-Taboada, F. 2017. Opioid-free anaesthesia in three dogs. Open Vet. J. 7, 104-110.

Williamson, A.J., Soares, J.H.N., Pavlisko, N.D., McAlister Council-Troche, R. and HenaoGuerrero, N. 2017. Isoflurane minimum alveolar 
concentration sparing effects of fentanyl in the dog. Vet. Anaesth. Analg. 44, 738-745.

Wilson, J., Doherty, T.J., Egger, C.M., Fidler, A., Cox, S. and Rohrbach, B. 2008. Effects of intravenous lidocaine, ketamine, and the combination on the minimum alveolar concentration of sevoflurane in dogs. Vet. Anaesth. Analg. 35, 289-296.
Yamashita, K., Furukawa, E., Itami, T., Ishizuka, T., Tamura, J. and Miyoshi, K. 2012. Minimum alveolar concentration for blunting adrenergic responses (MAC-BAR) of sevoflurane in dogs. J. Vet. Med. Sci. 74, 507-511. 